\title{
Artigos
}

\section{A questão de gênero na percepção do processo saúde-doença de pessoas privadas de liberdade em delegacias}

\author{
Gender issue in the perception of the health-disease process of people \\ detained in police stations (abstract: p. 17)
}

La cuestión de género en la percepción del proceso salud-enfermedad de personas privadas de libertad en comisarías (resumen: p. 17)

Ridiney Santos Oliveira(a)
<ridiney@bol.com.br> (D)
Rafaela Schaefer ${ }^{(b)}$
<rafaschaefer1@gmail.com>

Henrique Cesar Correa Hamilko(c)

<henriquehamilko@gmail.com> iD

Deivisson Vianna Dantas dos Santos ${ }^{(\mathrm{d})}$

<deivianna@gmail.com>

Sabrina Stefanello(e)

<binastefanello@gmail.com>

\author{
(a) Pós-graduando do Programa de \\ Mestrado em Saúde da Família \\ em Rede Nacional (Mestrado), \\ Universidade Federal do \\ Paraná (UFPR). Rua Padre \\ Camargo, 280, 3o andar, Alto \\ da Glória. Curitiba, PR, Brasil. \\ 80060-240. \\ (b) Graduanda do curso de \\ Medicina, UFPR. Curitiba, PR, \\ Brasil. \\ (c) Graduando do curso de \\ Medicina, UFPR. Curitiba, PR, \\ Brasil. \\ (d) Departamento de Saúde \\ Coletiva, UFPR. Curitiba, PR, \\ Brasil. \\ (e) Departamento de Medicina \\ Forense e Psiquiatria, UFPR. \\ Curitiba, PR, Brasil.
}

O estudo envolveu reclusos provisórios de delegacias de polícia de Curitiba, estado do Paraná, Brasil, uma masculina e outra feminina, com a finalidade de explorar diferenças entre gêneros e auxiliar em estratégias para incluir essa questão na abordagem dessa população na Atenção Básica (AB). Foi um estudo qualitativo baseado em observação participante, com diário de campo e 26 entrevista abertas audiogravadas (13 masculinas e 13 femininas), transcritas e analisadas pela fenomenologia hermenêutica de Ricoeur. $\mathrm{O}$ ambiente feminino era mais acolhedor, e a percepção de saúde-doença assumiu um caráter mais restrito ao biológico para os homens, enquanto para as mulheres teve conceitos ampliados. As mulheres sentiam falta da independência para buscar atendimento médico, pois frequentemente iam à Unidade Básica de Saúde (UBS) antes de serem presas, diferentemente dos homens. Ambiente, controle, relações e percepção do processo saúde-doença tiveram diferenças entre os gêneros.

Palavras-chave: Gênero. Percepção saúde-doença. População privada de liberdade. Presos. 


\section{Introdução}

Somente em 2014 a Política Nacional de Atenção Integral à Saúde das Pessoas Privadas de Liberdade no Sistema Prisional (PNAISP) incluiu as delegacias no atendimento em saúde das pessoas privadas de liberdade. A PNAISP propóe então o acesso à Rede de Atenção à Saúde (RAS) no território, seguindo os princípios do Sistema Único de Saúde (SUS), tendo a Atenção Básica (AB) como primordial no atendimento dessa população ${ }^{1}$. Portanto, é fundamental que os profissionais dos serviços de saúde, especialmente da $A B$, se aproximem da visão e da realidade dessas pessoas para qualificar as ações em saúde.

O Levantamento Nacional de Informações Penitenciárias divulgou que, até junho de 2016, a população prisional feminina era de 42.355 mulheres, das quais 1.268 se encontravam em delegacias, enquanto a população prisional masculina era de 665.482 e com 16.662 reclusos em delegacias. Das unidades prisionais brasileiras, $74 \%$ destinam-se aos homens, $7 \%$ ao público feminino e outras 17\% são mistas ${ }^{2}$. A delegacia é uma unidade policial para atendimento ao público, base e administração de operaçóes policiais, investigaçóes criminais e detenção temporária de suspeitos e presos em flagrante ${ }^{3}$. Ou seja, na delegacia encontram-se as presas e os presos provisórios.

Pertencer ao grupo privado de liberdade, no Brasil, influencia no processo saúdedoença, determinando condiçôes de vulnerabilidade e interferindo no acesso aos serviços de saúde. Para além da marginalização social causada pela privação de liberdade e por situações socioeconômicas, geralmente desfavoráveis, prévias à reclusão, recai sobre a mulher privada de liberdade uma terceira punição: os imperativos das normas de gênero, em um sistema historicamente patriarcal que impóe definições e prescrições do que é - ou deveria ser - a mulher ${ }^{4}$.

O presente trabalho explorou as diferenças entre os gêneros no ambiente de reclusão e percepção de saúde e doença em delegacias de uma grande cidade brasileira, quando atendidas por uma equipe de Saúde da Família (SF) de seu território.

\section{Metodologia}

Optou-se por realizar um estudo qualitativo em duas delegacias da cidade de Curitiba, uma masculina e outra feminina, selecionadas intencionalmente devido à facilidade de acesso do pesquisador.

Foram utilizadas duas ferramentas para a obtenção dos dados: a primeira foi a observação participante, com elaboração de diário de campo, no qual foram registrados aspectos como a relação dos reclusos e das reclusas entre si e com os profissionais da saúde e da delegacia, o manejo de cuidados de saúde, a maneira como se realizava o atendimento pela equipe de saúde e pelos funcionários da delegacia, e a estrutura física. A frequência da observação foi, em média, de duas vezes por semana e ocorria durante as entrevistas, os atendimentos da equipe de saúde e os procedimentos aos quais os reclusos e as reclusas eram submetidos, como nas transferências para outros setores do sistema prisional, nas escoltas até o advogado, entre outros. O tempo de permanência na delegacia foi em média de quatro horas por visita. Os registros foram feitos em caderno e caso ocorresse 
alguma situação que gerasse dúvida no pesquisador posteriormente era esclarecida com as pessoas envolvidas no atendimento naquele momento. Tal metodologia foi importante para complementar as entrevistas realizadas, que tiveram tempo médio de menos de dez minutos. A população privada de liberdade costuma falar pouco, além de apresentar medo de represálias de ambos os lados (de colegas de cela e policiais). Associada a esse medo, há a necessidade de liberar o policial para suas atividades na delegacia o mais rápido possível, determinando o pouco tempo das entrevistas. Logo, foi fundamental a complementação metodológica com observação participante e diário de campo.

A segunda forma de obtenção das informaçóes foi por meio de entrevistas abertas, em número de 26 (13 masculinas e 13 femininas), gravadas em áudio e depois transcritas integralmente. Primeiramente, foram formuladas algumas perguntas e discutidas entre o grupo de pesquisa; em seguida, foi feito um teste para verificar se as perguntas disparadoras eram capazes de extrair as informaçốes necessárias dos entrevistados. Após o teste-piloto, foram feitos ajustes, restando algumas perguntas relacionadas a como são entendidos os problemas de saúde, como o cuidado em saúde ocorre e como se dá o acesso aos profissionais de saúde.

O tamanho da amostra foi definido por saturação; portanto, a suspensão de inclusão de novos participantes ocorreu quando os dados obtidos passaram a apresentar, na avaliação do pesquisador, certa redundância ou repetição, não sendo considerado produtivo persistir na coleta 5 .

Os convites às pessoas privadas de liberdade para a participação no estudo foram feitos reservadamente pelo pesquisador durante o momento de saída da cela para algum procedimento solicitado pelos policiais. Para evitar exposição, somente aqueles que seriam transferidos ou sairiam em liberdade foram convidados a participar. $\mathrm{O}$ anonimato foi preservado nas entrevistas e na sua análise; qualquer informação que pudesse incorrer em identificação foi suprimida dos textos. Para preservar a identidade dos participantes e facilitar o reconhecimento de cada entrevista, optou-se por chamálos de $\mathrm{M}$ (masculinos) e F (femininos), enumerando-os.

A coleta de dados ocorreu em um período de seis meses. Não foram incluídas no estudo pessoas com clara dificuldade cognitiva, ou que representavam algum risco para o entrevistador, segundo avaliação dos guardas locais. Nenhuma pessoa convidada se recusou a participar.

Para as etapas seguintes, optou-se pela fenomenologia hermenêutica de Ricouer, utilizando-se o círculo hermenêutico para transcrição e construção de narrativas e da análisehermenêutica-dialética. Essas técnicas foram escolhidas para garantir maior validade dos sentidos e confiabilidade das interpretações, mantendo assim o rigor científico ${ }^{6}$.

A fenomenologia descreve o fato tal qual ele se permite conhecer. Trata-se de uma postura aberta do pesquisador para a compreensão da vivência do outro respeitando a singularidade de cada sujeito, buscando a compreensão e a interpretação de um fenômeno ${ }^{7}$. Enquanto a fenomenologia se envolve com a consciência e o mundo-vida do objeto de estudo, a hermenêutica de Ricouer tem como base de análise textos e discursos reconhecendo as crenças, os valores e a temporalidade do pesquisador, sendo, portanto, uma técnica que permite maior coerência, consistência e profundidade na interpretação, contribuindo para a análise fenomenológica ${ }^{8}$. 
$\mathrm{Na}$ transcrição, buscou-se apresentar não apenas o texto do discurso, mas também detalhes como pausas, risadas, aumento de tom de voz, mantendo-se o mais fiel possível à essência do que foi dito.

Em seguida, as transcriçóes foram transformadas em narrativas, passando o texto que estava em forma de entrevista para um discurso em primeira pessoa. Nessa etapa, foi importante compreender a polissemia da linguagem e do conhecimento das gírias utilizadas pelos reclusos. Para isso, o diário de campo proporcionou um material de apoio essencial, pois nele se apresentava muito da forma de ver o mundo dos entrevistados, assim como as gírias por eles utilizadas. Além disso, foi necessário em alguns momentos uma "tradução" do linguajar próprio utilizado pelas pessoas reclusas e pelos trabalhadores das delegacias, de modo que o texto se tornasse compreensível a todos.

Cada uma dessas narrativas foi posteriormente avaliada por pelo menos três pesquisadores, visando garantir o que seria uma mediação entre a experiência e o discurso, manter uma postura hermenêutica e assegurar a manutenção de sua temporalidade, evitando retirar sua cronologia ou meramente garantir lógica, duas importantes ressalvas feitas por Ricoeur?. Além disso, Ricouer admite que existem várias interpretaçóes que apresentam diferentes legitimidades, ou seja, é preciso que a interpretação proposta seja suficientemente vigorosa e consistente, a ponto de sobreviver ao conflito de interpretaçóes concorrentes ${ }^{8}$.

A análise dos dados, realizada por meio da leitura repetitiva das narrativas e do diário de campo do pesquisador, tinha como foco identificar as possíveis diferenças nos discursos e percepçôes que indicassem diferenças em relação ao gênero das pessoas em privação de liberdade. Por fim, construiu-se uma grade de análise com as categorias que emergiram dos textos. Dessas categorias foram extraídos os núcleos argumentais utilizados nos resultados.

Os participantes assinaram o Termo de Consentimento Livre e Esclarecido (TCLE), submetido ao Comitê de Ética da Universidade Federal do Paraná, aprovado com o registro na Plataforma Brasil CAAE 80355317.0.0000.0102. Todas as dúvidas dos participantes em relação à participação na pesquisa foram esclarecidas antes de iniciadas as entrevistas.

\section{Resultados e discussão}

Com base nas entrevistas e nos diários de campo, foi possível organizar os resultados nas seguintes categorias: "Cotidiano no cárcere: ambiente e relaçôes", "Gênero e percepção de saúde”, "Gênero e percepção de doença” e "Mulher invisível”.

\section{Cotidiano no cárcere: ambiente e relações}

$\mathrm{Na}$ delegacia feminina não havia divisão entre as celas conforme a gravidade dos delitos cometidos, e ficavam abertas com apenas a porta central fechada. O uso de algemas era raro e as reclusas se acomodavam com aproximadamente 25 mulheres no total. Foi observado um clima tranquilo no geral, com a agente de cadeia ouvindo as queixas das detentas e a equipe de enfermagem sendo mais acolhedora com elas em comparação com os reclusos masculinos. Percebeu-se menos insegurança entre os profissionais ao trabalhar com o grupo feminino do que com o grupo masculino. 
Já na delegacia masculina havia divisão entre as celas conforme a gravidade e a periculosidade dos delitos cometidos, albergando cerca de quatro vezes mais reclusos do que na delegacia feminina. O clima observado era mais agitado e tenso, com agentes de cadeia mais violentos e grande preocupação com a segurança, inclusive durante as consultas médicas, as quais eram rápidas para evitar um possível motim.

As taxas de comportamento violento são menores entre as mulheres do que entre os homens ${ }^{2}$, o que explica a diferença entre o número de reclusos em cada delegacia. $\mathrm{O}$ uso da violência pelas mulheres impressiona, pois se trata de inverter o papel social de inferioridade e vitimização que lhes é atribuído ${ }^{10}$. Esse fato foi observado na delegacia feminina, na medida em que trabalhadores da delegacia ficavam chocados por terem, entre as reclusas, uma dupla que havia cometido homicídio.

Atualmente, destacam-se dois perfis diferentes de criminalidade feminina: o de uma mulher fragilizada e vitimizada, que entra no mundo do crime para ajudar seu companheiro, seu irmão, seu filho, ou seja, usa como justificativa a submissão a uma figura masculina; e o de uma mulher que comete o crime por vontade autônoma e não se encaixa no papel de vítima, possuindo um perfil agressor e visando integrar o crime organizado $^{11}$. A aproximação dos sexos masculino e feminino ocorrida no universo social acarretou também a proximidade dos sexos nas práticas dentro do universo criminal ${ }^{12}$.

O diário de campo explicitou as relaçóes das pessoas privadas de liberdade entre si: havia uma sociedade organizada dentro do cárcere, com hierarquias definidas, valores sociais, normas próprias de conduta, comportamento e linguajar. Tal linguajar era mais difundido entre os reclusos. Havia também um sistema comercial em ambas as delegacias em que produtos trazidos pelas visitas se transformavam em moeda de troca.

No que concerne à relação entre as pessoas reclusas, percebeu-se uma solidariedade maior entre as mulheres do que entre os homens, exemplificada na fala seguinte, retirada das narrativas:

Quando a colega está quieta está com algum problema né, daí a gente tem que ajudar. (F08)

Na relação com os profissionais de saúde e da delegacia, evidenciou-se pelo diário de campo que as mulheres estavam mais receptivas a ajuda: houve uma abertura maior por parte delas, predominando conversas mais amistosas e contribuindo para resultados mais favoráveis no cuidado em saúde. Nas entrevistas elas se comunicaram melhor do que os homens e não houve clima de desconfiança, além de se expressarem mais e os profissionais da delegacia permitirem entrevistas mais longas. Já os homens só responderam o extremamente essencial quando entrevistados, e em suas relaçóes com os profissionais havia clima de desconfiança e ameaças.

$\mathrm{O}$ aspecto emotivo foi ressaltado frequentemente pelos profissionais da delegacia feminina, documentado em diário de campo. Ouviram-se comentários como: "trabalhar com mulheres presas, tem que cuidar com o que fala, senão já começa a choradeira", "não pode gritar muito como se faz com homem, pois mulher é muito escandalosa”. 
Verificou-se que as mulheres privadas de liberdade recebiam contraceptivos hormonais orais da equipe de saúde da família que as atendia para evitar a menstruação, como uma medida de higiene nas celas. Além do anticoncepcional, a delegacia tinha disponível analgésicos, antibióticos, pomadas para alergia e para tratamento ginecológico, medicamentos trazidos da UBS pelo médico responsável, pois não eram fornecidos diretamente pelo Estado.

No caso, os motivos para o uso do anticoncepcional evidenciam uma lógica que póe o bem-estar da instituição à frente das mulheres que lá estavam. Por mais que elas relatassem nas entrevistas que não eram obrigadas a tomar os anticoncepcionais e que até os desejavam, os motivos eram diversos do habitual no campo da saúde da mulher. Essa utilização de intervençôes ditas de saúde com indicação no mínimo heterodoxa pode ser considerada uma prática de medicalização social. O conceito de medicalização social foi definido como "a expansão progressiva do campo de intervenção da biomedicina por meio da redefinição de experiências e comportamentos humanos como se fossem problemas médicos”13 (p. 62). A expansão do saber médico e do atendimento de saúde como estratégia para "resolver" problemas humanos fora da esfera da saúde chegou a ponto de produzir um decréscimo geral no que chamou de índice de boa saúde: a capacidade de transformar, de forma autônoma, a própria vida e o meio em que se vive, com vistas a preservar ou aumentar o grau de "liberdade vivida" ${ }^{14}$.

Tal medicalização do corpo feminino pode tolher a liberdade de algumas mulheres em relação à possibilidade de entrar em contato com um período importante de seu ciclo feminino pela menstruação ${ }^{15} \mathrm{e}$ ainda ignorar os efeitos colaterais que podem ser causados pelos hormônios ${ }^{16}$. Além disso, tabagismo - prática comum entre as reclusas - também é um fator de risco para fenômenos tromboembólicos ${ }^{16}$, o que torna o uso de anticoncepcionais desaconselhável. Por outro lado, como as celas são ambientes com pouca privacidade e que não favorecem a higiene pessoal, esse recurso pode ser benéfico para diminuir o desconforto das reclusas e facilitar sua higiene. Essa dualidade torna a questão complexa e, a fim de impedir a repetição de sensos comuns sobre a que essa população pode ou não ter acesso, cabe a discussão sobre quais açóes uma equipe de saúde pode ofertar para melhorar o ambiente e quais são os desejos dessas sujeitas reclusas.

Contudo, muitas vezes, havia falta de medicamentos ou eles não eram disponibilizados pela equipe de saúde da $\mathrm{AB}$ de referência, devendo ser trazidos por amigos ou parentes nos dias de visita aos reclusos. Quando o detento não tinha alternativas para adquirir o medicamento, ficava na dependência da ajuda de colegas, como mencionado nas narrativas:

A gente paga um remédio uma pra outra aí, principalmente aquelas que não tem ninguém aqui. (F10)

Tem gente que é forasteiro, não tem visita, daí a gente ajuda o próximo, um ajuda o outro. (M23)

Quanto a medicamentos psicotrópicos não foi percebida prescrição na delegacia feminina, mas também em relação às mulheres entrevistadas não houve relatos de uso prévio. Já na delegacia masculina, pelas observaçôes registradas em diário de campo, 
havia a "liberação" de psicotrópicos para os que utilizavam previamente e para aqueles que eram excessivamente "belicosos e atiçadores", com o intuito de diminuir esse comportamento. A prática de medicalização dos comportamentos nesses ambientes não é nova e se mostra importante mesmo no caso de adolescentes em privação de liberdade, cumprindo medidas socioeducativas ${ }^{17}$. Mas é interessante perceber que pode ser uma prática também em delegacias, com a justificativa, no nosso caso, relacionada à segurança e à higiene. Fato esse que corrobora o estatuto da medicalização social, em que processos comuns da vida, como menstruação, envelhecimento e estar agitado ou revoltado com alguma situação, são cada vez mais apropriados pela medicina, tornando-se seu campo de saber/poder, possivelmente um meio de controle e regulação social ${ }^{14}$.

\section{Gênero e percepção de saúde e doença}

O gênero é definido de forma muito mais ampla, e não necessariamente coincide com o sexo biológico ${ }^{18}$. Já nos relatos do diário de campo percebemos que o critério de escolha do encaminhamento para as delegacias era por meio do sexo biológico, apesar de haver uma resolução oficial ${ }^{19}$ sobre o direito de escolher para qual unidade prisional, masculina ou feminina, a pessoa deseja ir, além da possibilidade de escolher ficar em separado, no caso de pessoas transexuais. Talvez por isso, somado ao estigma social e ao receio de falar em ambientes de privação de liberdade, entre os entrevistados as identidades sexuais coincidiram com o sexo biológico. Esses elementos podem ter levado a uma limitação do estudo em não se perceber nuances relacionadas à questão de gênero.

Dessa forma, ao analisar e comparar as entrevistas, verificou-se que para os homens a saúde assumiu um caráter muito mais de bem-estar físico - apesar de outras visões mais integrais também surgirem nos relatos; e duas são exemplificadas abaixo. A compreensão do processo de saúde dos homens foi voltada para o biológico segundo a autopercepção e o comportamento humano.

Já saúde é não ter nenhum tipo de doença, não é verdade? É fazer o exercício diário que dá para fazer, se exercitar, fazer flexão, se alimentar bem, tomar água. (M02)

E defino por saúde um bom atendimento médico, local adequado, dignidade, sem abalo do psicológico. (M24)

A percepção de saúde das mulheres apresentou uma visão mais ampliada e integral do que a percepção dos homens no geral. $\mathrm{Na}$ visão feminina de saúde apareceram muitos aspectos relacionados à saúde mental e social, à liberdade, à produtividade, à capacidade de comunicação e ao sentido da vida. No diário de campo percebeu-se que as participantes femininas tiveram mais dificuldade em definir o que consideram saúde, talvez por terem tido em mente esse conceito mais amplo, mais difícil de verbalizar. Essa percepção ampliada de saúde das mulheres já foi observada em outros estudos ${ }^{20,21}$. 
E saúde para mim é coisa boa, que seria ajudar o próximo, você ter saúde, você ter disposição, você poder trabalhar, você poder viver sua vida com saúde [...] (F08)

Muitas definiçóes do que seria saúde e estar saudável enalteceram a liberdade, o humor, e a capacidade de comunicação e de extroversão, tanto em entrevistas de mulheres quanto de homens privados de liberdade

Observou-se, também, que as pessoas presas eram mais caladas, introvertidas, falando somente o necessário. Ao correlacionar os relatos com o observado, as pessoas que vivem em situação de privação de liberdade não se consideram saudáveis, pois seus ideais de saúde e seus comportamentos no ambiente do cárcere foram absolutamente divergentes.

[...] Pra gente que vive aqui nesse lugar, assim, é difícil descrever a pessoa que tá com saúde, porque é muito... o psicológico da pessoa também, muda muito, a pessoa muda muito, a força da pessoa muda muito. (F11)

Esse e outros trechos, juntamente com as anotações do diário de campo, indicaram que a privação de liberdade seria adoecedora por inúmeros fatores. Restrição de liberdade, superpopulação, ambiente hostil e insalubre, falta de higiene do local e alta prevalência de doenças infectocontagiosas seriam algumas condiçóes que inviabilizariam a vida digna e contribuiriam para tal adoecimento.

Apesar de a percepção de saúde na esfera psicológica ter estado presente em relatos de ambos os gêneros, não houve procura por atendimento médico devido a queixas psíquicas, pois o sofrimento psíquico, ainda que citado, pareceu não ser percebido como motivo suficiente para suscitar a assistência à saúde ou para evidenciar que algo não vai bem, como já apontado em outra pesquisa ${ }^{22}$.

Adentrando em outra categorização, o fenômeno da saúde é visto como um fato, um atributo, uma função orgânica ou uma situação social, envolvendo determinados juízos de valor na medida em que pode ser definida negativa ou positivamente. Negativamente, a saúde significaria ausência de doenças, riscos, agravos e incapacidades; positivamente, denotaria desempenho, funcionalidades, capacidades e percepçóes ${ }^{23}$.

Tanto reclusas quanto reclusos representaram a saúde com aspectos positivos e negativos. Quando comparados com as mulheres, os homens tendem mais a definir saúde por meio de aspectos negativos, apesar de também a definirem positivamente. As mulheres focaram mais em definiçôes positivas do que os homens. Assim, ao contrário do que vemos na tradição de abordagem das questôes de saúde, na Atenção Primária (AP) o conceito mais recorrente e estabelecido era a saúde como ausência de dor ou doença. Tratavam saúde mais como "está sorrindo", "está bem” e não é preciso tomar medicamentos.

Tanto as entrevistas masculinas quanto as femininas definem como pessoas doentes as que são mais tristes e caladas. Identificar um doente na delegacia significa analisar como a pessoa é, age e se comporta. Entretanto, para os reclusos masculinos, apenas essa mudança de comportamento não era suficiente para referir que uma pessoa está doente, necessitando também apresentar algum sintoma físico: 
Você vê seu amigo brincando e conversando, daí depois ocê vê quieto, daí sabe que ele tá ruim. A gente vê quando tá quieto, tá com febre, tá com dor, reclama, a gente vê um colega tá doente. (M24)

Se ele ficar meio quietão assim, com dor, ele está doente, às vezes ele fica quieto daí eu ia perguntar se está com algum problema, com dor, alguma coisa. (M02)

Entre as mulheres foi mais comum a associação de doenças com questóes emocionais. Em diversos momentos do processo observacional da pesquisa o pesquisador se deparou com uma mulher chorando enquanto conversava com outra colega de cela ou com algum profissional da delegacia. Durante as consultas, diversas mulheres choraram, ou seja, foi mais fácil observar a evidência de tristeza entre as mulheres do que entre os homens, uma vez que a externalização do sofrimento emocional foi mais frequente. Talvez seja pelo fato de, dentro dos presídios, a depressão ser mais prevalente entre as mulheres ${ }^{24}$, ou a masculinidade na prisão reforçar a não reprodução de padrões de relação tidos como femininos, ou seja, falar demais de sentimentos, fraquezas e medos ${ }^{25}$. Além disso, quando as reclusas tentavam retratar o que seria uma pessoa doente, citavam alguém triste, isolado e quieto (aspectos emocionais), mesmo na ausência de sintomas físicos:

Se uma colega está doente, eu vejo desânimo, porque se você conhece a pessoa há muito tempo e de um dia pro outro ela fica desanimada, com vontade de fazer mais naaada, assim sabe? Daí eu acho que cada dia vai piorando. (F11)

Uma colega doente fica quieta, mais quieta. Ela fica quieta no canto, assim, sem conversar com ninguém, isolada sabe. (F12)

Por um lado, no caso das mulheres, por elas buscarem mais os serviços e falarem mais sobre si e seus problemas, os profissionais que as atendem estão propensos também a desqualificar a queixa ou a não relevar o seu sofrimento. No campo da saúde, por exemplo, é comum rotulá-las como "poliqueixosas", o que é uma forma de "inviabilizar" o problema do sofrimento mental ${ }^{26}$.

Percebeu-se maior dificuldade entre os reclusos em dar uma definição à doença. Os homens descreveram em seus discursos mais sintomas, tanto físicos quanto psíquicos. Mesmo tendo encontrado em ambas as delegacias uma dificuldade em definir doença, provavelmente isso não se deveu à reclusão em si, mas a algo prévio a ela, relacionado com o fato de essa população já ser vulnerável e marginalizada antes da reclusão. O perfil demográfico da população prisional brasileira decorre da marginalização histórica, da falta de políticas públicas inclusivas, da baixa escolaridade, da pouca perspectiva de futuro e da cultura da violência ${ }^{27}$. 


\section{Busca pelo atendimento de saúde}

Embora as mulheres considerassem sintomas psíquicos como doença, elas não relataram busca de atendimento para tais problemas nas delegacias. As reclusas falaram também que se sentiam acolhidas na delegacia, e que o apoio mútuo entre elas era um fator protetor para sua saúde mental, o que pode ter contribuído para a falta de busca de atendimento por queixas psíquicas.

Considerando que o acesso aos profissionais de saúde na delegacia era escasso, ele ainda passava por outros filtros existentes. Para além das necessidades prementes das reclusas, havia uma avaliação de necessidade realizada pelos guardas, e também as outras reclusas precisavam aceitar a demanda de qualquer uma das postulantes por atendimento de saúde. Dessa forma, pelas narrativas, foi possível perceber que as mulheres sentiam falta da independência que tinham antes de serem presas para buscar atendimento em saúde:

Aqui sou meio brecada, né, para pedir atendimento, tanto que é a primeira vez que eu estou me consultando. Acho que se tivéssemos atendimentos com mais frequência, seria melhor. Se tivessem um olhar, assim, com mais atenção pras presas, seria bom, pois aqui não é fácil não, é bem difícil o atendimento. (F5)

Fora daqui eu procurava atendimento médico nos postos de saúde. Aqui dentro a gente tem que chamar os guarda, né. (F16)

Essa "perda de liberdade" fica mais evidente quando relacionamos e contextualizamos a busca por atendimentos com a ligação dessas pessoas com o sistema de saúde previamente à reclusão. As mulheres relataram que se sentiam mais desassistidas que os homens, já que previamente à reclusão possuíam maior vínculo com os serviços de saúde, em contraste com os homens. Já eles não relataram tanto esse cuidado com a saúde antes da reclusão; disseram procurar atendimento quando sentiam dor ou outros sintomas que não melhoraram com o tempo ou o tratamento caseiro:

Quando eu estava fora daqui eu procurava atendimento indo no posto de saúde, isso acontecia quando eu tinha dor frequente, ferida no corpo. (M02)

Fora daqui eu procurava ajuda em último caso, não fazia preventivo. (M19)

Diferentemente dos homens - que tendiam a retardar ao máximo a busca por assistência na saúde -, as mulheres iam mais frequentemente ao médico para prevenção ou ao menor dos sintomas. Isso ocorre devido a aspectos culturais, como a representação do cuidar como tarefa feminina e a da "invulnerabilidade masculina" 28 .

Percebeu-se entre as reclusas, também, uma maior preocupação com a limpeza de celas, tentativa de manter o ambiente limpo e higienizado, lavagem de roupas, local separado para secá-las e intensa adesão ao período de vacinação contra gripe. O mesmo grau de cuidado 
e preocupação não foi identificado no ambiente masculino. Tal tipo de cuidado feminino é relatado na literatura, a qual observou cuidados com a alimentação, exercícios físicos e hidratação entre as reclusas ${ }^{29}$. Uma hipótese seria a de tentar transformar o espaço que é hostil e desconhecido em um ambiente similar ao do cotidiano doméstico conhecido. Daí os cuidados com a arrumação do espaço para transformá-lo o mais próximo possível de uma casa $^{30}$. Mas também esse cuidado pode ser entendido como uma das formas para suportar o sofrimento em ambientes de encarceramento ${ }^{31}$.

Entretanto, tal movimento reforça os estereótipos da estruturação machista de nossa sociedade, na qual os homens crescem entendendo que se cuidar deve ser uma preocupação feminina ${ }^{32}$. O que torna essa tarefa, seja do cuidar delas, seja do cuidar dos outros, incluindo os homens, invariavelmente a cargo das mulheres. O que por um lado reflete em melhores indicadores de saúde, por outro mostra maior opressão social e maior carga de atividades consideradas inerentemente responsáveis ${ }^{33,34}$.

\section{A mulher invisível}

Tanto homens como mulheres dependiam de suas famílias e de pessoas fora das delegacias, conforme fragmentos retirados das narrativas:

[...] porque eu não tenho advogado, eu não tenho, sabe, desespero total, então eu dependo que vocês venham aqui, depende de você, não tem como, depende de vocês mesmo, não tem família, né. (F18)

Se você não tem família, você morre aqui dentro!!! (M01)

Percebeu-se que as funcionárias da delegacia colaboravam com as detentas trazendo produtos de higiene pessoal e íntima por conta própria, pois observavam o abandono por parte das pessoas que eram próximas às reclusas antes da prisão.

Como observado, as mulheres privadas de liberdade recebiam menos visitas nas delegacias do que os homens. Houve maior movimentação de pessoas visitando os reclusos masculinos, geralmente visitas femininas (mães, esposas, filhas), usualmente levando itens de higiene pessoal, mantimentos, roupas e cigarro. Esse predomínio de visitantes femininas foi descrito em outros artigos ${ }^{12,29}$.

Todavia, percebeu-se que algumas mulheres não achavam ruim não receber visita. Comentavam que tinham vergonha da situação em que se encontravam. Muitas detentas também achavam muito "humilhante" a revista pelas quais as visitas passam, achando melhor que elas não aparecessem ${ }^{31}$. Por outro lado, a solidariedade entre as reclusas era mais evidente por meio de trocas de utensílios de uso pessoal, medicamentos ou mesmo pela própria postura mais acolhedora. Os grupos e o suporte mútuo entre pares representam um caminho importante para a construção de estratégias coletivas de resistência para as mulheres ${ }^{35}$. O fato de muitas identificarem o ambiente da delegacia às vezes mais seguro e acolhedor revela a triste realidade de que, por vezes, a opressão e a violência sofridas pelas mulheres na sociedade podem ser até maiores do que a circunstância da privação de liberdade. 
Pelo diário de campo, pode-se perceber que muitas mulheres se sentiam abandonadas pela família, principalmente por marido e companheiro, que no geral não aceitavam o fato de elas estarem em situação de privação de liberdade. Quando recebiam visitas, assim como na delegacia masculina, normalmente as visitas eram de outras mulheres, como mãe, filhas e irmãs.

A prevalência de visitas femininas em ambas as delegacias reforça a normativa de que cabe à mulher o papel de cuidadora, construída mediante relaçôes de gênero desiguais relacionadas ao machismo estrutural da nossa sociedade ${ }^{32}$. Estima-se que, mundialmente, três quartos dos trabalhos não remunerados de cuidados sejam realizados por mulheres. Enquanto elas dedicam, no geral, quatro horas e 25 minutos por dia nesse trabalho de cuidado, eles dedicam, em média, uma hora e 23 minutos; 3,2 vezes menos ${ }^{36}$.

Muitas mulheres perdem a guarda dos filhos enquanto reclusas ${ }^{2}$. Um exemplo retirado do diário de campo foi o de uma detenta que, ao ser presa, perdeu por completo o contato com suas filhas. Familiares assumiram os cuidados e não informaram à mãe onde estavam suas crianças, o que foi relatado como um motivo de sofrimento para a entrevistada. Além disso, como as mulheres privadas de liberdade eram as principais cuidadoras dos filhos, a reclusão reflete em consequências para além das sujeitas presas, afetando a vida dos filhos e a desestabilização dos vínculos familiares ${ }^{37}$.

As visitas reforçam os laços com a família: ao manter contato com pessoas externas, sentem que não foram excluídos e excluídas da comunidade ${ }^{38}$. São também um suporte para as adversidades do cárcere e estímulo para reintegração social. Além do mais, a visita da família tem importância para diminuir o processo de prisionização, que seria o processo de socialização no cárcere, no qual o recluso adquire costumes e hábitos no ambiente de privação de liberdade ${ }^{31}$, como aumento do consumo de tabaco, ociosidade e negligência com a saúde ${ }^{29}$.

As visitas são importantes não apenas pelos aspectos emocionais, mas também pela qualidade de vida dentro das celas, pois era nesses momentos que os familiares levavam utensílios de que os reclusos necessitavam. Houve relatos de mulheres privadas de liberdade que não recebiam nenhuma ajuda da família e dependiam exclusivamente do Estado, não recebendo itens que poderiam proporcionar pequeno conforto e afeto simbólico ${ }^{38}$.

A rejeição moral por estarem presas é muito maior para as mulheres que para os homens ${ }^{31}$. As mulheres privadas de liberdade acabam violando duplamente o papel social destinado ao gênero feminino em uma sociedade patriarcal e machista como a nossa, resultando em maior exclusão social quando comparadas aos homens, como observado. Violação tanto da representação materna que restringe o papel das mulheres nas políticas públicas como a própria entrada em um mundo esperado que seja de domínio exclusivamente masculino, como é o caso da criminalidade ${ }^{38}$.

Isso poderia agravar ainda mais a sensação de solidão e depressão entre as reclusas, visto que, como analisado anteriormente, elas possuem uma percepção de saúde que envolveu muito mais aspectos psicossociais. Como a visita seria uma oportunidade de comunicação com o ambiente externo, diminuindo a sensação de reclusão, permitindo assim a diminuição do processo de prisionização e da sensação de exclusão, ela permitiria à pessoa 
privada de liberdade ter um suporte para conseguir lidar com o aprisionamento. Porém, como as mulheres receberam menos visitas, houve um processo de condenação maior para elas do que para os homens; logo, houve o peso da condenação jurídica e da social.

Como limitaçóes, o presente estudo não pode ser generalizado para todas as delegacias, já que cada uma apresenta diferentes profissionais e tipos de reclusos e é responsável por trabalhar com crimes distintos, apresentando, assim, características diferentes. Além disso, temos o possível viés de um dos pesquisadores trabalhar diretamente com essa população, mas isso foi minimizado pelo trabalho em equipe do grupo de pesquisa, pois outros pesquisadores que não faziam parte da rotina da delegacia foram os que realizaram as análises das narrativas. Também haviam encontros regulares para discutir o andamento da pesquisa, mantendo a crítica e os múltiplos olhares em relação à interpretação dos dados.

\section{Conclusão}

Além de estratégias próprias para as delegacias e da flexibilidade de terem de ir ao local onde estão os reclusos e reclusas, as equipes de saúde da família precisam planejar açôes e abordagens com diferentes enfoques conforme cada ambiente.

Alguns pontos relevantes foram: (1) maior preocupação por cuidados de saúde pelas reclusas do que pelos reclusos no momento prévio à prisão; (2) uma visão mais ampliada e integral de saúde das mulheres do que a percepção dos homens no geral; (3) entre o sexo feminino, a reclusão impediu a independência na busca por atendimento em saúde, causando maior sentimento de desassistência do que entre os homens; e (4) as mulheres recebiam menos visitas, o que reforça o sentimento de desamparo, indicando uma condenação não só jurídica, mas também social.

Se os dois primeiros pontos ajudam na compreensão do porquê o ambiente na delegacia feminina era claramente mais acolhedor, com maior solidariedade e receptividade entre o sexo feminino, os dois outros pontos subsequentes se apresentam como barreiras a serem transpostas.

Dessa forma, as equipes da $\mathrm{AB}$ devem ter um conhecimento melhor de como a privação de liberdade é conduzida no país: não há um aspecto ressocializador como é o idealizado em documentos nacionais, e sim opressão e condições subumanas de vida, que adoecem os indivíduos e tolhem suas capacidades individuais e sociais. Além disso, não há como deixar de fora os aspectos inerentes à nossa sociedade, como as práticas de dominação, a discriminação e a violência de gênero que têm impacto significativo na vida das pessoas e são reproduzidas durante a reclusão. 


\section{Contribuições dos autores}

Todos os autores participaram ativamente de todas as etapas de elaboração do manuscrito.

\section{Conflito de interesse}

Os autores não têm conflito de interesse a declarar.

\section{Direitos autorais}

Este artigo está licenciado sob a Licença Internacional Creative Commons 4.0, tipo BY (https://creativecommons.org/licenses/by/4.0/deed.pt_BR).

\section{(cc) BY}

\section{Editora}

Rosamaria Giatti Carneiro

Editora associada

Stela Nazareth Meneghel

Submetido em

13/04/20

Aprovado em

23/08/20

\section{Referências}

1. Lermen HS, Gil BL, Cunico SD, Jesus LO. Saúde no cárcere: análise das políticas sociais de saúde voltadas à população prisional brasileira. Physis. 2015; 25(3):905-24.

2. Brasil. Ministério da Justiça. Departamento Penitenciário Nacional - DEPEN Informações Penitenciárias (INFOPEN) [Internet]. Brasília: Ministério da Justiça; 2018 [citado em 2 Fev 2019]. Disponível em: http://depen.gov.br/DEPEN/depen/ sisdepen/infopen-mulheres

3. Silva $\mathrm{AB}$. Delegacia de polícia não é cadeia pública [Internet]. Campo Grande: Correio do Estado; 2015 [citado 20 Fev 2019]. Disponível em: https://www.correiodoestado. com.br/opiniao/delegacia-de-policia-nao-e-cadeia-publica/243957/

4. Carvalho DTP, Mayorga C. Contribuições feministas para os estudos acerca do aprisionamento de mulheres. Estud Fem. 2017; 25(1):95-116.

5. Barcellos FBJ, Magdaleno JR. Saturação teórica em pesquisas qualitativas: contribuiçôes psicanalíticas. Psicol Estud. 2012; 17(1):63-71.

6. Oliveira MM. Metodologia interativa: um processo hermenêutico dialético. Interfaces Bras/Can. 2001; 1(1):67-78.

7. Gonzáles AD, Garanhani ML, Bortoletto MSS. Fenomenologia Heideggeriana como referencial para estudos sobre formação em saúde. Interface (Botucatu). 2012; 16(42):809-17. 
8. Melo MLA. Contribuiçóes da hermenêutica de Paul Ricoeur à pesquisa fenomenológica em psicologia. Psicol USP. 2016; 27(2):296-306.

9. Ricoeur P. Mundo do texto e mundo do leitor. In: Ricoeur P. Tempo e narrativa. Campinas: Papirus; 1997. p. 320-7.

10. Martins IR. A criminalização feminina: o lugar da mulher no crime [monografia]. Brasília: Universidade de Brasília; 2016.

11. Santos VES. Mulheres criminosas: a evolução do discurso de vitimização da criminalidade de gênero em face a inserção da mulher no crime organizado. In: Anais CONIDIF; 2017; Campina Grande. Campina Grande: Realize Editora; 2017.

12. Silva LMS, Silva BM. Além cárcere: consequências metajurídicas da criminalidade feminina no Brasil. Rev Eletronica Jus [Internet]. 2016 [citado 30 Out 2018]. Disponível em: https://jus.com.br/artigos/46571/alem-carcere-consequenciasmetajuridicas-da-criminlidade-feminina-no-brasil

13. Tesser CD. Medicalização social (I): o excessivo sucesso do epistemicídio moderno na saúde. Interface (Botucatu). 2006; 10(19):61-76.

14. Gaudenzi P, Ortega F. O estatuto da medicalização e as interpretaçốes de Ivan Illich e Michel Foucault como ferramentas conceituais para o estudo da desmedicalização. Interface (Botucatu). 2012; 16(40):21-34.

15. Vieira EM. A medicalização do corpo feminino. Rio de Janeiro: Fiocruz; 2015.

16. Almeida APF, Assis MM. Efeitos colaterais e alteraçôes fisiológicas relacionadas ao uso contínuo de anticoncepcionais hormonais orais. Rev Eletronica Atualiza Saude. 2017; 5(5):85-93.

17. Costa ND, Silva PR. A atenção em saúde mental aos adolescentes em conflito com a lei no Brasil. Cienc Saude Colet. 2017; 22(5):1467-78.

18. Pedro JM. Traduzindo o debate: o uso da categoria gênero na pesquisa histórica. Historia (São Paulo). 2005; 24(1):77-98.

19. Brasil. Conselho Nacional de Combate à Discriminação. Resolução Conjunta no 1 , de 15 de Abril de 2014. Estabelecer os parâmetros de acolhimento de LGBT em privação de liberdade no Brasil. Diário Oficial de União. 17 Abr 2014.

20. Mamede MV, Bueno JV, Bueno S. Percepção da condição de saúde entre mulheres. Rev Bras Enferm. 1993; 46(2):95-100.

21. Martins ELC, Martins LG, Silveira AM, Melo EM. O contraditório direito à saúde de pessoas em privação de liberdade: o caso de uma unidade prisional de Minas Gerais. Saude Soc. 2014; 23(4):1222-34.

22. Diuana V, Lhuilier D, Sánchez AR, Amado G, Araújo L, Duarte AM, et al. Saúde em prisões: representaçôes e práticas dos agentes de segurança penitenciária no Rio de Janeiro, Brasil. Cad Saude Publica. 2008; 24(8):1887-96.

23. Silva AL, Ferreira J. O que é saúde? Interface (Botucatu). 2013; 17(47):983-6.

24. Constantino P, Assis SG, Pinto LW. O impacto da prisão na saúde mental dos presos do estado do Rio de Janeiro, Brasil. Cienc Saude Colet. 2016; 21(7):2089-100.

25. Santos HB, Nardi HC. Masculinidades entre matar e morrer: o que a saúde tem a ver com isso? Physis. 2014; 24(3):931-49.

26. Pedrosa M, Zanello V. (In)visibilidade da violência contra as mulheres na saúde mental. Psicol Teor Pesqui. 2016; 32(214):1-8. 
27. Soares Filho MM, Bueno PMMG. Demografia, vulnerabilidades e direito à saúde da população prisional brasileira. Cienc Saude Colet. 2016; 21(7):1999-2010.

28. Schraiber LB, Figueiredo WS, Gomes R, Couto MT, Pinheiro TF, Machin R, et al. Necessidades de saúde e masculinidades: atenção primária no cuidado aos homens. Cad Saude Publica. 2010; 26(5):961-70.

29. Santos MV, Alves VH, Pereira AV, Rodrigues DP, Marchiori GRS, Guerra JVV. The physical health of women deprived of their freedom in a prison in the state of Rio de Janeiro. Esc Anna Nery. 2017; 21(2):e20170033.

30. Gomes R, Nascimento EF, Araújo FC. Por que os homens buscam menos os serviços de saúde do que as mulheres? As explicaçóes de homens com baixa escolaridade e homens com ensino superior. Cad Saude Publica. 2007; 23(3):565-74.

31. Frinhani FMD. Mulheres encarceradas e espaço prisional: uma análise de representaçóes sociais. Psicol Teor Prat. 2005; 7(1):61-79.

32. González DF. Entre público, privado e político: avanços das mulheres e machismo velado no Brasil. Cad Pesqui. 2014; 44(151):239-43.

33. Botton A, Cúnico SD, Strey MN. Diferenças de gênero no acesso aos serviços de saúde: problematizaçóes necessárias. Mudancas Psicol Saude. 2017; 25(1):67-72.

34. Courtenay W. Constructions of masculinity and their influence on men's well-being: a theory of gender and health. Soc Sci Med. 2000; 50(10):1385-401.

35. Meneghel SN, Barbiani R, Brener C, Teixeira G, Sttefen H, Silva LB, et al. Cotidiano ritualizado: grupos de mulheres no enfrentamento à violência de gênero. Cienc Saude Colet. 2005; 10(1):111-8.

36. International Labour Office. Care work and care jobs for the future of decent work. Geneva: ILO; 2018.

37. Pereira EL. Famílias de mulheres presas, promoção da saúde e acesso às políticas sociais no Distrito Federal, Brasil. Cienc Saude Colet. 2016; 21(7):2123-34.

38. Scherer ZAP, Scherer EA, Santos MA, Souza J, Pillon SC, SN Pires. Mulheres privadas de liberdade: representações sociais de prisão, violência e suas consequências. Rev Bras Enferm. 2020; 73(3):e20180781. 
The study involved provisional detainees from two Curitiba police stations, state of Paraná, Brazil, one for males and one for females, to explore gender differences in this environment and to develop strategies to include gender in addressing this population in Primary Care. It was a qualitative study based on participant observation keeping a field diary, and 26 transcribed open interviews (13 male and 13 female), transformed into narratives and later into a grid for analysis. The female environment was more welcoming, and the perception of health-disease assumed a more strictly biological character for men, while women had more expanded concepts. Women missed the independence to seek medical attention because, unlike men, they were used to go to the Basic Health Unit before prison. Environment, control and relationships, as well as the perception of the health-disease process had gender differences.

Keywords: Gender. Health-disease perception. People deprived of freedom. Prisoners.

El estudio envolvió a reclusos (as) provisionales de comisarías de policía de Curitiba, estado de Paraná, Brasil, una masculina y otra femenina, con la finalidad de explorar diferencias entre géneros y auxiliar en estrategias para incluir la cuestión de género en el abordaje de esta población en la Atención Básica. Fue un estudio cualitativo basado en observación participativa, con diario de campo y en 26 entrevistas abiertas audiograbadas (13 masculinas y 13 femeninas), transcritas y analizadas por la fenomenología hermenéutica de Ricoeur. El ambiente femenino era más acogedor y la percepción de salud-enfermedad asumió un carácter más restricto a lo biológico para los hombres, mientras que las mujeres tuvieron conceptos ampliados. Las mujeres sentían falta de independencia para buscar atención médica, puesto que frecuentemente iban a la Unidad Básica de Salud antes de ser presas, diferentemente de los hombres. Ambiente, control, relaciones y percepción del proceso saludenfermedad tenían diferencia entre los géneros.

Palabras clave: Género. Percepción salud-enfermedad. Población privada de libertad. Presos. 